\title{
Valve-sparing aortic root replacement: Surgeon and patient factors contribute to long-term durability
}

\author{
John S. Ikonomidis, MD, PhD
}

\author{
From the Division of Cardiothoracic Surgery, Medical University of South Carolina, Charleston, SC. \\ Disclosures: Author has nothing to disclose with regard to commercial support. \\ Received for publication Nov 4, 2016; accepted for publication Nov 4, 2016; available ahead of print Dec 5, 2016. \\ Address for reprints: John S. Ikonomidis, MD, PhD, Division of Cardiothoracic Surgery, Suite BM 282, 114 \\ Doughty St, Charleston, SC 29425 (E-mail: ikonomij@musc.edu). \\ J Thorac Cardiovasc Surg 2017;153:230-1 \\ $0022-5223 / \$ 36.00$ \\ Copyright (C) 2016 by The American Association for Thoracic Surgery \\ http://dx.doi.org/10.1016/j.jtcvs.2016.11.017
}

In 1979 , acting on the observation that many patients presenting for aortic root replacement have normal aortic valve morphology, Sir Magdi Yacoub developed a strategy for aortic root replacement (the "remodeling procedure") in which the aortic valve is preserved. ${ }^{1}$ In 1988, Dr Tirone David introduced a different technique for valve-sparing aortic root replacement, the reimplantation procedure, which in contrast to the remodeling procedure stabilizes the aortic valve annulus with a subannular row of horizontal mattress sutures attached to the Dacron polyester fabric graft encasing the valve. ${ }^{2}$ The remodeling procedure is easier to perform, but time has shown that, especially in patients with annuloaortic ectasia, the operation will fail in many cases because of development of aortic valve insufficiency as the unprotected annulus continues to remodel and dilate.

The degree of success afforded by the reimplantation modification is showcased in this issue of The Journal of Thoracic and Cardiovascular Surgery, in which David and colleagues ${ }^{3}$ present their series of 333 patients during a 23 year period, all of whom underwent a valve-sparing root replacement with the implantation (David) technique. The mean follow-up was more than 10 years, and it extended to 15 years for 39 patients. Patients were young (mean age was $46 \pm 5$ years) and predominantly male $(78 \%)$. The aortic root aneurysm was associated with Marfan syndrome in 124 of the patients $(37 \%)$, and a congenitally bicuspid aortic valve was present in 45 patients. Twenty-eight patients had type A aortic dissections. The aortic degree of aortic insufficiency was moderate or severe in 144 patients. There were 4 early deaths ( $<90$ days, $0.1 \%$ mortality) and 35 late deaths. Survivals at 15 and 20 years were $77.9 \% \pm 2.9 \%$ and $72.4 \% \pm 3.8 \%$, respectively. Only 11 patients had development of moderate or severe aortic regurgitation during the follow-up; with interval censoring, $96.2 \% \pm 1.0 \%$ were free from this event at 15 to 20 years. Six patients underwent reoperations on the aortic valve, for a freedom from reoperation at 15 to 20 years of $96.9 \% \pm 1.3 \%$.

These are the best results in the world for this operation. The US National Marfan Foundation has suggested as a

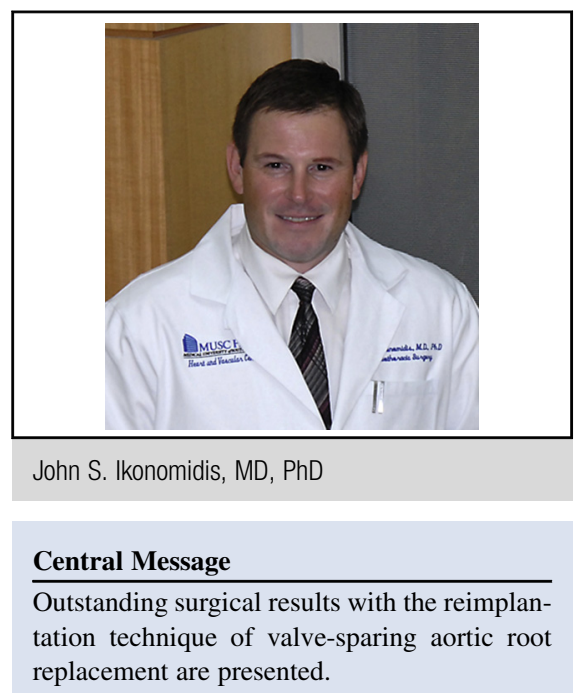

See Article page 232.

standard that valve-sparing aortic root replacement operations should only be performed at centers where the operative mortality is less than $1 \%$ and the 10 -year freedom from valve reoperation exceeds $90 \% .{ }^{4}$ Most centers will not attain these lofty recommendations, but some, such as the Toronto $^{3}$ and Stanford $^{5}$ programs, have achieved this mark and beyond. The keys to superlative results such as these include appropriate patient referrals and the performance of the operation by highly skilled surgeons who have great experience with this procedure. As David and colleagues $^{3}$ discuss in their article, the ideal patient has a relatively small $(<55 \mathrm{~mm})$ aortic root and grossly normal cusps on surgical inspection. The ability to operate on these patients depends on cardiologists who are well educated in the importance of early referral to achieve the best results, and an important factor in these referrals is the degree of confidence that referring cardiologists have in the capabilities of their surgeon. A collaborative, multidisciplinary consideration of these patients on both the medical and surgical sides is thus critical to having the optimal patient taken to the operating room for best results.

I have written in the past on how this operation can be modified in several places to make it more user friendly, especially to facilitate resident teaching, but the fact remains that this operation is a highly complex geometric exercise that alters the shape and diameter of the aortoventricular junction, the shape of the aortic valve cusp attachments to the aorta, and the valve commissural 
heights when the Dacron polyester fabric graft is implanted, and the resultant impact on the geometry and coaptation of the valve cusps must be anticipated, identified, and repaired when appropriate. This is precisely where the "art" of this procedure lies. Some years ago, after having performed around 50 valve-sparing root reimplantation operations myself, I visited Dr David in Toronto to observe his technique. I recall one particular operation during this visit where, after placement of the Dacron polyester fabric graft and suturing of the pericusp aorta to the graft, the valve seemed to sit perfectly to my eye. Yet Dr David was not satisfied. He remarked to me that one cusp coapted just slightly lower than the others and that overall he was concerned that there would not be a sufficient coaptation distance ( $>5 \mathrm{~mm}$ is ideal) for the operation to be durable. What ensued was another 20 to 30 minutes in which Dr David made subtle modifications to the cusps to produce the ideal result in his mind. The valve worked perfectly, with a low gradient and no aortic insufficiency. I took much from that day and have used his teachings fastidiously. Surely, observations and repairs such as these made by Dr David during the years have contributed greatly to his group's results.

This article by David and colleagues ${ }^{3}$ will likely change my practice of using polytetrafluoroethylene sutures to reinforce and elevate the aortic cusp free margin (which was shown with univariable analysis to predict development of moderate to severe aortic insufficiency) in favor of cusp plication. I was also interested in their finding that surgically created neoaortic sinuses in the Dacron polyester fabric graft were associated with development of late significant regurgitation. I personally have always used a straight Dacron polyester fabric graft and will continue to do so. The presence of a congenitally bicuspid aortic valve usually requires that some sort of intervention be performed on the valve cusps after the Dacron polyester fabric graft is placed, especially the conjoined cusp, which tends to prolapse in to the left ventricular outflow tract after the Dacron polyester fabric graft is implanted. In this series of David and colleagues, ${ }^{3}$ however, bicuspid aortic valve did not contribute as a predictor of aortic insufficiency. The excellent results reported here are supported by similarly favorable outcomes in this patient population at other experienced centers. ${ }^{7,8}$

To conclude, the reimplantation technique of valvesparing aortic root replacement has positively affected the lives of many young people all over the world with aortic root annuloaortic ectasia. Those of us who perform this operation must read this article carefully and absorb its massages. I would also recommend a visit to Toronto to see $\mathrm{Dr}$ David perform these operations-you will not regret this decision!

\section{References}

1. Yacoub MH, Gehle P, Chandrasekaran V, Birks EJ, Child A, Radley-Smith R. Late results of a valve-preserving operation in patients with aneurysms of the ascending aorta and root. J Thorac Cardiovasc Surg. 1998;5:1080-90.

2. David TE, Feindel CM. An aortic valve-sparing operation for patients with aortic incompetence and aneurysm of the ascending aorta. J Thorac Cardiovasc Surg. 1992;103:617-21; discussion 622.

3. David TE, David CM, Feindel CM, Manlhiot C. Reimplantation of the aortic valve at 20 years. J Thorac Cardiovasc Surg. 2017;153:232-8.

4. Coselli JS, Volguina IV, LeMaire SA, Sundt TM, Connolly HM, Stephens EH et al. Aortic Valve Operative Outcomes in Marfan Patients Study Group. Early and 1-year outcomes of aortic root surgery in patients with Marfan syndrome: a prospective, multicenter, comparative study. J Thorac Cardiovasc Surg. 2014; 147:1758-66. 1767.e1-4.

5. Miller DC. Rationale and results of the Stanford modification of the David V reimplantation technique for valve-sparing aortic root replacement. J Thorac Cardiovasc Surg. 2015;149:112-4.

6. Ikonomidis JS. Valve-sparing aortic root replacement- "T. David V" method. Op Tech Thorac Cardiovasc Surg. 2009;14:281-96.

7. de Kerchove L, Boodhwani M, Glineur D, Vandyck M, Vanoverschelde JL, Noirhomme P, et al. Valve sparing-root replacement with the reimplantation technique to increase the durability of bicuspid aortic valve repair. $J$ Thorac Cardiovasc Surg. 2011;142:1430-8

8. Bavaria JE, Desai N, Szeto WY, Komlo C, Rhode T, Wallen T, et al. Valve-sparing root reimplantation and leaflet repair in a bicuspid aortic valve: comparison with the 3-cusp David procedure. J Thorac Cardiovasc Surg. 2015;149(2 Suppl):S22-8. 